\title{
6
}

\section{CORPUS PARA PESQUISAS EM INGLÊS COMO LÍNGUA FRANCA (ILF): ONDE ESTAMOS E PARA ONDE VAMOS}

\author{
CORPUS FOR RESEARCH IN ENGLISH AS A LINGUA \\ FRANCA: WHERE WE ARE AND WHERE WE ARE \\ HEADING TO.
}

\author{
Ana Beatriz Almeida 1 \\ Universidade Federal da Bahia \\ Lucielen Porfirio ${ }^{2}$ \\ Universidade Federal da Bahia
}

\begin{abstract}
Resumo: O Inglês como Língua Franca (ILF) surge de interações em contextos comunicativos multilíngues nos quais o Inglês é conhecido pelos falantes e está sempre na mistura durante a interação (JENKINS, 2015). Para compreender ILF, corpora disponibilizaram dados empíricos para pesquisas em vários locais do mundo (VOICE, 2001; ELFA, 2004). Com o aumento de estudos em ILF no Brasil, Gimenez e Bordini (2014) notaram uma lacuna em estudos empíricos com uma perspectiva local de ILF. Assim, apresentamos um mapeamento de pesquisas com base em corpora em ILF no Brasil entre 2001 e 2018. Para isso, foram realizadas buscas na plataforma CAPES, Google Scholar e referências dos trabalhos analisados com foco em Inglês como Língua Franca, Inglês como Língua Internacional e pesquisa de corpus. A partir dos resultados encontrados, sugerimos um banco de dados com interações em ILF ocorridas no país visando fornecer subsídios para trabalhos locais ou em uma escala mais abrangente.
\end{abstract}

Palavras-Chave: Inglês como Língua Franca; Corpus; Mapeamento; Dados empíricos.

1 Endereço eletrônico: almeidabibia1117@gmail.com.

2 Endereço eletrônico: lucielenporfirio@hotmail.com. 
Abstract: English as a lingua franca (ELF) arises from interactions in multilingual communicative contexts in which English is known by speakers and is always in the mix during the interaction (JENKINS, 2015). In order to understand ELF, corpora provided empirical data for research in multiple places around the world (VOICE, 2001; ELFA, 2004). With the increase in studies on ELF in Brazil, Gimenez e Bordini (2014) noticed a gap in empirical studies with a local perspective of ELF. Thus, we present a mapping of researches based on corpora in ELF in Brazil between 2001 and 2018. For this, searches were carried out on the CAPES platform, Google Scholar and references of the analyzed works focusing on English as a Lingua Franca, English as an international language and corpus research. From the results found, we suggest a database with ELF interactions that occurred in the country in order to provide subsidies for local works or on a more comprehensive scale.

Keywords: English as a Lingua Franca; Corpus; Mapping; Empirical data.

\section{INTRODUÇÃO}

Com a evolução das pesquisas em Inglês como Língua Franca (ILF) no mundo, estudos com base em dados empíricos para compreender o processo de comunicação entre falantes de línguas diferentes por meio do inglês vai se desenvolvendo e necessitando de novas reflexões. Assim, muitos pesquisadores na área de ILF recorrem a corpora já conhecidos e consolidados tais como o VOICE - Vienna-Oxford International Corpus of English e o ELFA - English as a Lingua Franca in Academic Settings, os quais têm sido de extrema importância na evolução das pesquisas em ILF (JENKINS, 2015).

A consciência sobre o inglês que emerge em contextos comunicativos multilíngues nos quais essa língua é conhecida por todos os envolvidos (JENKINS, 2015) é cada vez mais estudada entre pesquisadores de todos os lugares. No Brasil, conforme indica Gimenez (2015), percebe-se um crescimento em trabalhos com essa perspectiva. No entanto, há, para a autora, uma lacuna de estudos no Brasil que trabalhem com dados empíricos com um valor local para fornecer subsídios a pesquisadores da área de ILF.

Compreendendo que os estudos baseados em corpora são, de fato, altamente importantes para a compreensão dos usos do inglês com valores mais locais, o objetivo deste artigo é apresentar avanços e lacunas nos estudos 
brasileiros a partir de um mapeamento de pesquisas realizadas com corpus com perspectiva em ILF. Para realizar a pesquisa, partimos do estudo de Gimenez e Bordini (2014), mas incluímos um levantamento de estudos com base em corpus, sejam eles coletados para pesquisas localizadas ou em grandes escalas, o que não era o objetivo da referida autora. Através dos resultados encontrados, separamos e analisamos aqueles que poderiam nos auxiliar a traçar o mapeamento de pesquisas em corpus em ILF no Brasil.

Neste artigo, falamos rapidamente sobre a evolução dos estudos em ILF ao longo dos anos e como essa perspectiva tem sido trabalhada em território brasileiro. Discutimos um mapeamento já realizado com pesquisas em ILF no Brasil e os resultados obtidos com tal pesquisa, com o intuito de evidenciar a importância da construção de um corpus brasileiro ILF para subsidiar os trabalhos cada vez mais crescentes que, pela dificuldade da coleta de dados empíricos, acabam voltando-se para uma abordagem teórica e/ou de cunho pedagógico.

\section{INGLÊS COMO LÍNGUA FRANCA}

A expansão do inglês transformou o idioma em um fenômeno global, e a língua, que antes se acreditava pertencer apenas a seus falantes nativos - em especial aos falantes de origem de países do círculo interno ${ }^{3}$ (KACHRU, 1985) começa a se espalhar entre falantes de diferentes primeiras línguas. A expansão do inglês tomou tamanha proporção que, segundo Seidlhofer (2011), quatro entre cinco de seus falantes pertencem a países em que a língua não é oficial ou nativa.

\footnotetext{
3 Na tentativa de categorização da expansão da LI no mundo, Kachru (1985) propõe a denominação de três círculos concêntricos: círculo interno onde a língua inglesa funciona como uma L1 (ou língua nativa) (ex.: Reino Unido, Estados Unidos, Canadá); em segundo lugar, o círculo externo onde o idioma foi impingido aos povos subjugados pelo poderio britânico (ex. África do Sul, Índia); e, em terceiro lugar, o círculo em expansão onde o inglês é estudado como língua estrangeira (ex. China, Brasil).
} 
Há vários motivos para isso, entre eles, em especial, o fato de que a língua inglesa tem se tornado, no mundo que vivemos, a língua de produções acadêmicocientíficas, da tecnologia, do cinema, negócios, economia, entre outros contextos possíveis.

À proporção que o número de usuários do inglês cresce exponencialmente, pesquisas que investigam a comunicação entre esses falantes também aumentam de forma significativa. O campo de pesquisa de Inglês como Língua Franca (ILF) entende a língua inglesa como qualquer uso de Inglês entre falantes de diferentes primeiras línguas para quem essa língua é o meio de comunicação escolhido para interação (SEIDLHOFER, 2011). Ainda nesse campo de pesquisa, o inglês é compreendido como uma ferramenta de comunicação em contextos multilíngues, nos quais a língua é conhecida pelos usuários em interação e frequentemente é uma escolha em potencial para que os falantes efetivem a comunicação (JENKINS, 2015). Sendo assim, o campo de estudos ILF procura demonstrar a diversidade nas formas de comunicação em língua inglesa, o que abrange um uso de práticas colaborativas (geralmente multilíngues) na interação, a criatividade, a negociação e a coparticipação de sentidos construídos e partilhados na língua (COGO, 2012).

Jenkins (2015) propõe, de uma forma geral, a divisão dos estudos de ILF em três fases: na primeira fase, busca-se compreender a inteligibilidade entre falantes diversos por meio do mapeamento de algumas características de pronúncia e usos lexicais e/ou gramaticais da língua, através do trabalho de Língua Franca Core (LFC) (JENKINS, 2001), muito embora apresentar um modelo monolítico da língua não era nem de longe sua intenção. Nessa fase, surgiram as primeiras propostas de construção de corpus que considerassem a perspectiva de ILF, tais como o VOICE (Vienna-Oxford International Corpus of English) e o ELFA (English as a Lingua Franca in Academic Settings); num segundo momento, os trabalhos de Seidlhofer (2011), baseados no VOICE, apontam para 
a necessidade de se desconstruir a ideia de uma possível codificação de ILF. Nesse período, também, pesquisadores passaram a se concentrar na negociação dada entre os interlocutores e no uso dos repertórios linguísticos durante a interação. Desta maneira, na fase 2, ILF é entendido como qualquer uso da língua inglesa em que os falantes de diferentes primeiras línguas interagem entre si por meio do inglês, sendo que esta é frequentemente a língua escolhida para a interação e frequentemente a única opção (SEIDLHOFER, 2011); já na terceira fase, ainda em estágio inicial, Jenkins (2015) propõe a intensificação das investigações a respeito da natureza multilíngue da comunicação em ILF, com a proposta do "Inglês como MultiLíngua Franca", uma língua usada em "contextos comunicativos multilíngues nos quais o Inglês é conhecido por todos os envolvidos, e está, portanto, sempre na mistura durante a interação, independente de quanto ou se ele é de fato utilizado ${ }^{\prime \prime}$ (JENKINS, 2015, p. 27).

A partir do ponto de vista de Jenkins (2015), percebemos que o uso do inglês pelo mundo tem se concretizado geralmente por pessoas multilíngues e que negociam sentidos durante a interação. Para os pesquisadores em ILF, tem sido importante compreender melhor a maneira como os falantes constroem um uso pragmático da língua - ao invés de estarem preocupados com a forma - para atingir uma comunicação eficaz que transborda os limites de fronteiras geográficas ou de sistemas gramaticais descritivos da língua. Nesse sentido, destacamos o fato de que a pesquisa em ILF tem encorajado a percepção do ambiente de diversidade, formações linguísticas variadas, experiências, e inovações dos falantes ao utilizar a língua inglesa.

O objetivo das pesquisas que consideram interações empíricas em ILF seria então “descrever a maneira que a língua é manipulada em formatos inovadores para se adequar às necessidades comunicativas de falantes que

\footnotetext{
4 Do original: "English as a Multilingua Franca refers to multilingual communicative settings in which English is known to everyone present, and is therefore always potentially 'in the mix', regardless of whether or not, and how much, it is actually used".
} 
interagem em comunidades de prática multilíngue [...]" (DEWEY; JENKINS, 2010, p. 106-107) ${ }^{5}$. Os estudos do VOICE (2013) ajudaram a reconhecer que ILF deve ser visto como um modo de comunicação que considera a negociação, flexibilidade, fluidez, adaptação e interação cultural e contextual entre os falantes. Assim, estudos com corpus são capazes de fornecer dados reais e relevantes para que as pesquisas continuem (re)pensando as características das interações ILF, bem como (re)construir uma proposta de uso da língua que possa melhorar a percepção do ensino, uso e pesquisa em língua inglesa.

\section{PESQUISAS DE CORPUS EM ILF}

Corpus é uma coleção de textos escritos ou orais - transcritos -, ocorridos naturalmente na língua, escolhidos para caracterizar um estado de variedade linguística, disponibilizados em formato digital (PRODROUMOU, 2008). A disponibilidade de amostras de língua torna-se, muitas vezes, essencial para o pesquisador, que pode usá-las como material para embasar seus argumentos e construir seus apontamentos.

As pesquisas de corpus que surgiram na perspectiva de ILF têm ajudado a catalogar algumas das muitas semelhanças e diferenças presentes na comunicação entre falantes de diferentes primeiras línguas. Contudo, foi a partir de pesquisas baseadas em corpora (JENKINS, 2015) que os pesquisadores começaram a amadurecer o conceito de ILF e perceberam que seria impossível catalogar todas as variações, visto que a língua é fluida e imprevisível e cada falante é único. Alguns dos corpora essenciais para o avanço dessas pesquisas são:

1) VOICE (Vienna-Oxford International Corpus of English), criado por Barbara Seidlhofer (2001-2007), é a primeira coleção estruturada de dados

\footnotetext{
5 Do original: "our purpose is to describe how the language is manipulated in innovative ways to suit the communicative needs of speakers who interact in complex multilingual communities of practice [...]" (JENKINS, 2015, p. 27).
} 
linguísticos em plataforma digital que procura gravar interações orais em ILF. Para acessar o corpus é necessário criar um login e senha. As interações são apresentadas com contexto e informações básicas, tais como número de palavras, tempo de interação e contexto onde foram gravadas, por exemplo.

2) ELFA (English as a Lingua Franca in Academic Settings), criado por Ana Mauranen (2004-2008), é composto por um milhão de palavras gravadas de interações orais em ILF no contexto acadêmico. Para ter acesso ao acervo, é necessário fazer uma solicitação, então o pesquisador recebe por e-mail o áudio e todos os dados transcritos, enviados de uma só vez, sem a descrição de contexto.

3) ACE (Asian Corpus of English), criado por Andy Kirkpatrick (20092014), com um milhão de palavras em interações de ILF no território asiático. Grande parte do corpus é de um contexto acadêmico e as transcrições ficam disponíveis na plataforma, mas a maioria dos áudios não é disponibilizada, sendo necessário enviar o pedido aos coordenadores do site.

O surgimento de corpora de ILF iniciou-se através de pesquisas motivadas pelos estudos de Jenkins (2001) com o LFC, dando lugar a bancos de dados como VOICE (2001) e ELFA (2004), que servem de inspiração para novos corpora localizados em outras universidades e países. Gostaríamos de ressaltar o surgimento do ViMELF - Video ELF Mediated (2018), um corpus de interações em ILF que, além do diferencial de serem mediadas por vídeo, disponibilizam o background linguístico do falante, tão importante para estudos multilíngues.

É necessário ressaltar, contudo, que o ILF, sendo uma língua de contato, se apresenta de diferentes formas, com diferentes estratégias de inteligibilidade e diversos tipos de falantes que dão características específicas à comunicação a depender do contexto em que se encontram. Assim, da mesma forma que reconhecemos a importância desses corpora para estudos do mundo inteiro, 
precisamos reconhecer também o valor de um corpus que possibilite entender comunicações e interações mais locais em determinados contextos.

Como veremos abaixo, as pesquisas em ILF vêm crescendo gradativamente também no Brasil. Começa-se a perceber, portanto, uma necessidade da disponibilização de dados empíricos que sirvam de subsídios para esses pesquisadores alavancarem ainda mais seus estudos, além de proporcionar um diálogo entre as especificidades do inglês falado produzido em território brasileiro com pesquisadores de outras universidades do mundo.

\section{AS PESQUISAS EM ILF NO BRASIL}

Conforme exposto acima, as pesquisas em ILF vêm crescendo em vários lugares do mundo, com a perspectiva de pensar a língua inglesa como fluída, variável, multilíngue. Vários estudos realizados também se preocupam com o ensino de LI, focalizando na questão de que é preciso desvincular o ensino do modelo de falante nativo, uma vez que esse falante já não pode mais ser visto como o único padrão a ser seguido para o ensino de línguas.

Reflexões e discussões sobre como o conceito de ILF pode afetar o professor de inglês têm chamado cada vez mais atenção de estudiosos da linguística aplicada interessados em ILF. Para demonstrar alguns dos impactos de ILF para o ensino-aprendizagem de língua inglesa, Gimenez; El Kadri; Calvo; Siqueira; Porfirio (2015) analisam os desenvolvimentos recentes em ILF, a partir das pesquisas observadas no ELF76 ${ }^{6}$ e indicaram que as implicações pedagógicas de ILF parecem ser o destaque principal no evento.

Em um mapeamento feito por Gimenez e Bordini (2014) sobre estudos feitos em ILF no Brasil entre 2005 e 2012, a autora faz uma análise sistemática de 67 trabalhos encontrados, nos quais, entre os assuntos abordados, encontram-se

\footnotetext{
$6 \quad 7^{\circ}$ Congresso Internacional de Inglês como Língua Franca ocorrido em 2014.
} 
temas como: crenças e atitudes de estudantes e professores, currículo L1, discussão conceitual, língua inglesa na globalização, ferramentas tecnológicas, formação de professores, identidade, inteligibilidade, materiais didáticos, pragmática, ensino de inglês no contexto ILF, etc. Uma das observações feita pela autora em seu estudo foi que, mesmo com o crescimento das publicações em ILF no período em análise, há algumas lacunas que precisam ser preenchidas.

Do total de 67 trabalhos analisados, 41 se configuram como ensaísticos, com foco em reflexões do(s) autor(es), enquanto 26 se caracterizaram como empíricos. Isto pode explicar a grande concentração na categoria "Reflexões sobre o ensino de inglês no contexto de ILF". Assim, uma possível lacuna, portanto, é a de trabalhos investigando as características de interações envolvendo brasileiros e falantes de outras línguas. Esses seriam dados que poderiam compor acervos como o do VOICE, por exemplo, permitindo que pesquisadores busquem regularidades, de modo a subsidiar professores. (GIMENEZ; BORDINI, 2014, p. 29, grifo nosso)

Acreditamos que pesquisas de corpus em ILF em território brasileiro seriam um dos primeiros passos para preencher essa lacuna. Os dados produzidos por essas pesquisas poderiam sim compor acervos como o VOICE, mas também poderiam compor um acervo nosso, um corpus brasileiro de ILF. Tendo por base o mapeamento feito por Gimenez e Bordini (2014), tivemos a intenção de traçar uma pesquisa mais específica, analisando os trabalhos produzidos no Brasil que têm por base apenas dados empíricos. Nesse sentido, utilizamos uma metodologia similar à de Gimenez e Bordini (2014) com algumas alterações para delinear como os teóricos brasileiros têm construído pesquisas em ILF com base em estudos de corpus. 


\section{CORPUS DE LÍNGUA INGLESA NO BRASIL: ONDE ESTAMOS E PARA ONDE VAMOS}

Conforme exposto até aqui, nosso objetivo com esse estudo é fazer um levantamento de trabalhos de pesquisas em corpus de língua inglesa em território brasileiro. Para tanto usamos os seguintes passos metodológicos:

1) Usamos as mesmas plataformas de buscas propostas por Gimenez e Bordini (2014), sendo elas: bancos de dissertações e teses da CAPES e Google Scholar. No entanto, quando localizamos títulos de trabalhos que poderiam indicar estudos de corpus e/ou ILF na plataforma lattes que não continham resumo ou informações mais específicas, usamos também o Google para buscar maiores detalhes sobre essas pesquisas. Consideramos apenas os estudos que focalizavam a perspectiva em ILF para a análise e os que não conseguimos identificar maiores informações (para além do título) foram descartados.

2) Focamos no período de 2001 a 2018, utilizando as palavras-chave "Inglês como Língua internacional”, "Inglês como Língua Franca", já usadas pelo estudo conduzido por Gimenez e Bordini (2014) e adicionamos as palavras-chave "corpus" e "corpus de língua inglesa", uma vez que esse é nosso foco principal.

3) Após acharmos alguns resultados, foi preciso selecionar os que se encaixavam no nosso objetivo, ou seja, fizemos um recorte para incluir apenas os estudos que apresentavam uma perspectiva que utilizasse um corpus local/brasileiro para fundamentar pesquisas em estudos linguísticos ${ }^{7}$ em língua inglesa. Para essa seleção, alguns critérios foram utilizados: a) selecionar todas as pesquisas acadêmicas que apresentassem

\footnotetext{
7 É importante lembrar que o foco deste mapeamento é em estudos de aprendizagem de LI ou em estudos linguísticos em LI e que descartamos os trabalhos com foco em literatura de LI ou em tradução.
} 
corpora orais, que usam ou não a perspectiva de ILF (isso foi feito com a intenção de aprofundar a análise dos trabalhos e perceber se era possível estabelecer um diálogo entre o corpus coletado e os estudos em ILF); b) selecionar estudos com corpora escritos ou orais de aprendizes de língua inglesa em território brasileiro, que utilizem ou não a perspectiva de ILF; c) trabalhos com corpus de pesquisadores que, apesar de coletarem interações de falantes apenas do português, adotaram a perspectiva de ILF.

4) Nos estudos selecionados, fizemos também uma análise das referências bibliográficas apresentadas, com o intuito de observar estudos feitos no Brasil que, por algum motivo, não estavam sendo apresentados pelas fontes de busca eletrônicas. A partir dessa análise, os estudos indicados nas bibliografias dos artigos sob análise e que pudessem se encaixar no foco do mapeamento foram inseridos para pesquisa no Google para procura de maiores informações, e eventualmente incluídos na discussão. Apresentamos, de forma geral, os primeiros resultados do mapeamento: 
Tabela 1: Trabalhos encontrados sobre ILF entre 2001 e 2018

\begin{tabular}{|c|c|c|}
\hline $\begin{array}{l}\text { PALAVRAS- } \\
\text { CHAVE }\end{array}$ & $\begin{array}{l}\text { FONTES DE } \\
\text { BUSCA }\end{array}$ & RESULTADOS \\
\hline "Inglês como & Bancos de & CoMAprend (TAGNIN, 2002) \\
\hline $\begin{array}{l}\text { Língua } \\
\text { internacional” }\end{array}$ & $\begin{array}{l}\text { dissertações e } \\
\text { teses da Capes }\end{array}$ & $\begin{array}{l}\text { Competência linguística comunicativa } \\
\text { (MENONCIN, 2013) }\end{array}$ \\
\hline “Inglês como & & $\begin{array}{l}\text { Inglês como Língua Franca e inteligibilidade de } \\
\text { fala (OLIVEIRA, 2014) }\end{array}$ \\
\hline $\begin{array}{l}\text { Língua } \\
\text { Franca"” }\end{array}$ & & Os sintagmas nominais do inglês \\
\hline “corpus" & & $\begin{array}{l}\text { (WRIGHT, 2014) } \\
\text { Os Phrasal Verbs na Produção Escrita de } \\
\text { Aprendizes Brasileiros de Inglês como Segunda } \\
\text { Língua: uma Análise Baseada em Corpus (COSTA, } \\
\text { 2017) }\end{array}$ \\
\hline \multirow{2}{*}{$\begin{array}{l}\text { “corpus de } \\
\text { língua } \\
\text { inglesa" }\end{array}$} & $\begin{array}{l}\text { Google } \\
\text { Scholars }\end{array}$ & $\begin{array}{c}\text { Conversational competence in English as a second } \\
\text { language (CORSETTI, 2015) } \\
\text { Cafés do Brasil (GINEZI, 2008) } \\
\end{array}$ \\
\hline & $\begin{array}{l}\text { Análise das } \\
\text { Referências } \\
\text { bibliográficas } \\
\text { dos trabalhos } \\
\text { selecionados }\end{array}$ & $\begin{array}{l}\text { Análise das etapas de elaboração de um curso de } \\
\text { Inglês com Fins Acadêmicos (ALVES, 2014) } \\
\text { Marcadores discursivos em entrevistas com } \\
\text { falantes nativos e não nativos da língua Inglesa } \\
\text { (CAMPOS; BURGO, 2015) }\end{array}$ \\
\hline
\end{tabular}

O projeto de Tagnin (2002), CoMET - Corpus Multilíngue para Ensino e Tradução, foi desenvolvido junto ao Departamento de Letras Modernas da Faculdade de Filosofia, Letras e Ciências Humanas da USP. Trata-se de um corpus eletrônico multilíngue de aprendizagem que tem o objetivo de dar suporte às pesquisas linguísticas nas áreas de Tradução, Terminologia e Ensino e Aprendizagem de Línguas, detectando dificuldades comuns dos aprendizes, na tentativa de promover percepções sobre a efetividade de diferentes metodologias para ensino. É dividido em três subcorpora, sendo eles CorTec - Corpus TécnicoCientífico; o CorTrad - Corpus de tradução, também dividido em Literário, Técnico-Científico e Jornalístico; e o CoMAprend - Corpus de Aprendizes. O 
CoMET conta com acervos de palavras catalogadas retiradas de textos escritos. No caso do CoMAprend, por exemplo, os aprendizes inserem redações no site e o professor/pesquisador pode, então, construir um subcorpus de aprendizes. Apesar de ser um trabalho interessante sobre coleta de corpus de aprendizes de inglês no Brasil, não encontramos nada a respeito da perspectiva de ILF no projeto. Esse fato pode ser explicado justamente porque a preocupação da autora está mais voltada à tradução e terminologia num primeiro momento e só pretende começar a se preocupar com o ensino em fases subsequentes do projeto.

Na dissertação de Menoncin (2013), temos uma pesquisa com aspectos linguísticos e socioculturais, que tem o objetivo de analisar as competências comunicativas - gramatical, sociolinguística, discursiva - de falantes em uma empresa comercial através da perspectiva de ILF. O corpus foi feito com oito funcionários dessa empresa por meio de entrevistas direcionadas - usando como suporte estudos sobre variabilidade sociolinguística (pesquisa qualitativa) - e textos escritos - análise dos memorandos redigidos pelos funcionários sobre as negociações e interlocuções com os clientes. A partir da análise desse material, a autora indica os diferentes níveis de competências e habilidades de comunicação desses funcionários. Em seus resultados, percebeu que a maior parte dos entrevistados compreende e fala muito bem o inglês em suas interações comunicativas com clientes estrangeiros no contexto profissional. Nesse trabalho, a perspectiva ILF está bem marcada e embasada e a autora apresenta discussões interessantes sobre a maneira como seus informantes constroem interação sem se preocupar com modelos de falantes nativos, o que reforça a importância de se usar corpus orais e locais para a realização de pesquisas em ILF. A autora produz um corpus pequeno em um contexto bem específico para sua pesquisa, o que a permite fazer considerações valiosas a respeito do uso, interação e comunicabilidade da língua em um ambiente real. 
O trabalho de Oliveira (2014) tem como objetivo investigar, elencar e discutir os aspectos relacionados à inteligibilidade de fala na perspectiva de ILF de brasileiros fluentes de língua inglesa. Para isso, a pesquisadora coletou um corpus local de interações de cinco brasileiros, que gravaram amostras de falas espontâneas em inglês. As amostras foram analisadas de duas formas: (1) avaliação da inteligibilidade de fala de ouvintes de diferentes nacionalidades em escala de cinco pontos entre o "nada compreensível" e o "totalmente compreensível"; e (2) avaliação fonético-acústica, que é uma análise auditiva e fonética, utilizando como base o Alfabeto Fonético Internacional (AFI). A partir das análises dos dados obtidos, a pesquisadora indica as particularidades da língua materna que o brasileiro fluente de ILF carrega em sua pronúncia e demonstra como a presença dessas características não afetou a inteligibilidade durante a comunicação. No trabalho de Oliveira (2014) também é possível perceber a importância do uso de corpus específicos coletados para pesquisas com ILF para demonstrar a maneira como falantes usam a língua e conseguem efetuar interações.

O objetivo da dissertação de Wright (2014) é investigar o uso de determinantes dos sintagmas nominais por aprendizes brasileiros de inglês na escrita acadêmica e compará-los com escrita acadêmica de falantes nativos do inglês, com o intuito de observar as diferenças de produções entre nativos de língua inglesa e brasileiros, mas, de acordo com a autora, sem olhá-las como erros, mas sim como preferências e tendências dos falantes ou como influências do português na segunda língua aprendida pelos brasileiros. Para isso, utilizou ferramentas computacionais de linguística de corpus, que processaram os dados dos corpora de referência e de estudo, respectivamente o de inglês nativo LOCNESS (The Louvain Corpus of Native English Essays), e o de inglês produzido no Brasil, BR-ICLE. A pesquisadora percebeu, a partir dos resultados, que a escrita acadêmica dos aprendizes apresenta semelhança e diferenças com a 
escrita acadêmica dos nativos. Nos resultados apontados, ela demonstra que parte dos sintagmas nominais foi utilizada de forma semelhante entre nativos e não nativos, tais como os numerais, os determinantes indefinidos e possessivos, assim como o uso do zero artigo. Nesse trabalho analisado, já conseguimos observar a comparação da língua produzida por brasileiros com a língua produzida por falantes nativos (apenas os falantes da variedade padrão de um corpus específico). Embora a autora diga claramente em seu trabalho que não pretende olhar as diferenças como deficiências, o fato de comparar uma língua produzida por brasileiros com uma língua de falantes nativos (padrão) não está em consonância com a perspectiva ILF, pois para essa área o inglês é produzido na interação a partir de diferentes backgrounds linguísticos de ambos e que auxiliam na construção da interação. Nessa linha de raciocínio, o importante seria a língua produzida para a comunicação dentro de contextos específicos de produção e não a comparação entre não nativos e nativos.

O trabalho de Costa (2017) procura investigar o uso dos phrasal verbs em produções escritas de aprendizes brasileiros da língua inglesa, comparando com produções feitas por aprendizes nativos. A pesquisa, qualitativa e quantitativa, usa os corpora BrICLE, para estudo, e LOCNESS e BNC, para referência. Em termos de comparação, o estudo mostrou que há semelhanças e diferenças entre os grupos analisados no emprego de phrasal verbs, e que os mais utilizados pelos nativos são também, em sua maioria, os mais utilizados pelos não nativos. Contudo, os aprendizes brasileiros, muitas vezes, aplicam esses verbos de forma diferente dos nativos, o que a autora aponta como um desacordo em relação aos padrões da língua inglesa. O estudo não se relaciona com a teoria do ILF, pois tem uma abordagem comparativa entre nativos e não nativos, analisando as produções a partir da norma padrão da língua inglesa, enquanto o ILF se preocupa com a efetividade da comunicação. 
Focando no aprendiz de línguas, abordando a Pragmática da Interlíngua e discutindo modelos de competência comunicativa e definições de competência conversacional, a tese de Corsetti (2015) justifica e propõe um modelo de competência conversacional em L2, no campo da Pragmática de Interlíngua, através de três componentes: o gerenciamento do discurso, a negociação do significado ilocucionário e a implementação de práticas conversacionais, utilizando alguns subcorpora orais oriundos do The BNC Sampler e The Diachronic Corpus of Present-Day Spoken English, empregados como corpora de referência de inglês britânico. Para tal proposta, foram coletados dados de vinte aprendizes brasileiros do nível CEFR Bi+ durante o período de um ano e meio, em um curso geral de língua inglesa no sul do Brasil, onde foram feitas as entrevistas. Coletadas as entrevistas, houve a análise dos advérbios mais comuns utilizados para mediar segmentos de discurso em conversas, os "hedges" adverbiais explícitos e implícitos mais comuns utilizados para mitigar atos de fala representativos e as partículas de resposta mínimas utilizadas pelo interlocutor para expressar uma boa receptividade. As investigações focalizaram os marcadores pragmáticos well, really, actually, maybe, probably, just, yeah e uhuh (CORSETTI, 2015).

Os marcadores really e yeah foram empregados, em suas funções discursivas e pragmáticas, com frequências adequadas pelos aprendizes brasileiros. $\mathrm{O}$ advérbio "maybe" foi sobre-utilizado, sinalizando uma tendência para a utilização de formas adverbiais para expressar epistemicidade, ao invés de verbos modais. (CORSETTI, 2015, p. 6)

Assim como no trabalho de Wright (2014), relatado acima, este trabalho apresenta uma perspectiva de comparação da língua de falantes brasileiros com um corpus de referência britânico. A preocupação nesse caso é comparar com um inglês padrão para apresentar as diferenças, mas numa perspectiva comparativa e suscetível a chamarmos de "erro" ou "influência" da língua nativa. Na 
perspectiva ILF, a língua dos falantes e todo o seu repertório linguístico são elementos que fazem parte da prática multilíngue com falantes de outras línguas maternas e são elementos de suma importância para a construção de interação ao invés de serem considerados como "influência” numa perspectiva comparativa.

A dissertação de Ginezi (2008) não utiliza a perspectiva de ILF, porém apresenta um corpus oral local em língua inglesa com interações entre falantes de diferentes nacionalidades. Com o objetivo de analisar a ocorrência de variantes terminológicas na linguagem de especialidade do Café e verificar a possibilidade de se construir um glossário bilíngue. As coletas têm base na oralidade e a pesquisadora compila dois corpora - um em português e outro em inglês - com o tema Café, composto por entrevistas face-a-face da pesquisadora com profissionais da área cafeeira e por conversações entre profissionais, em ambas as línguas. Construiu também um corpus bilíngue composto por interpretações entre falantes de inglês e de português, incluindo intérpretes durante a interação, para então analisar os dados dos corpora, procurando variantes terminológicas no contexto Café, subdividido em colheita e processamento. A partir dos dados coletados, da construção dos corpora e da análise dos mesmos, a pesquisadora elaborou um vocabulário bilíngue que inclui palavras que se enquadram na terminologia, com o objetivo de "auxiliar tradutores, intérpretes e profissionais da área cafeeira com um produto técnico, visto que há poucos termos de vulgarização ou científicos. Há, no total, 178 verbetes incluídos, contando cada variante, em língua portuguesa" (GINEZI, 2008, p. 169). Embora a autora não apresente necessariamente uma consonância com a perspectiva ILF, é possível perceber o foco dado na construção de uma variedade bem localizada de uso da língua a partir de usuários reais e que apresentam comunicação imediata com objetivos bem específicos.

O Br-ICLE, trabalho de Sardinha (2004), compreende um dos corpora de língua inglesa mais conhecidos no Brasil, e que se configura como uma extensão 
brasileira do ICLE (International Corpus of Learner English) - corpora de textos escritos coletados de algumas universidades colaboradoras e escritos por aprendizes de inglês de quatorze línguas nativas diferentes. Em conjunto com o projeto Br-ICLE, há um corpus de inglês criado na PUC/SP, no âmbito do projeto DIRECT, o Banco de Inglês (2004). O corpus conta com mais de 190 milhões de palavras de inglês oral e escrito até agosto de 2004, subdivididas em inglês geral e inglês de negócio, e faz parte do banco de dados do CEPRIL (Centro de Pesquisa, Recursos e Informação em Linguagem), fundado em 1983, ligado ao LAEL (Programa Pós-Graduação em Linguística Aplicada e Estudos da Linguagem), fundado em 1970, com o objetivo de servir como sede para o Projeto Ensino de Inglês Instrumental em Universidades Brasileiras. Além de não conseguirmos identificar a informação se o projeto considera ou não a perspectiva ILF, tivemos algumas dificuldades de acesso ao material, tais como o acesso ao site e o contato com a secretaria do LAEL, o que nos impediu de fazer análises mais detalhadas sobre o corpus em si.

O trabalho de Alves (2014) tem três objetivos principais: a) angariar material teórico e leituras sobre o ensino de língua estrangeira para fins acadêmicos; b) preparar um curso sobre esse formato de leitura na plataforma virtual Moodle; e c) compilar um corpus dos resumos em português e inglês criados no curso para atividades didáticas. Para isso, a autora estudou o material didático escrito por Swales e Feak (2009) e adaptou para o público do curso; também desenvolveu exercícios de escrita acadêmica para a produção de resumos acadêmicos em LI; coletou um documento de autorização escrito por parte dos alunos do curso para que seus textos fossem disponibilizados na plataforma Moodle e corrigidos em forma de peer-correction; utilizou resumos científicos em LI produzidos pelos alunos brasileiros para a compilação do corpus; coletou os textos dos alunos, separando-os de acordo com cada área e 
subdividindo-os em diferentes subcorpora do corpus técnico-científico BrasCiTec (ALVES, 2014).

É importante lembrar que chegamos à pesquisa de Alves (2014) a partir da análise das referências bibliográficas de um dos artigos selecionados e não a partir da apresentação no Google Acadêmico ou Capes. Mesmo com a metodologia e os objetivos bem referenciados, não conseguimos saber informações básicas tais como o número de participantes e suas nacionalidades. Acreditamos, porém, que o corpus foi produzido através dos textos de alunos de English for Academic Purposes (EAP) e que todos sejam brasileiros. O foco da pesquisa de Alves está voltado ao aprendizado de inglês com fins acadêmicos, o que deixa o trabalho mais voltado para a especificidade da leitura e escrita. É importante destacar que a criação de corpora produzidos por alunos brasileiros para a apresentação como atividades didáticas para a sala de aula podem ser aspectos importantes para o estudo de ILF, pois visam apresentar textos reais produzidos localmente pelos usuários da língua.

Campos e Burgo (2015) seguem, em sua pesquisa, o método empíricoindutivo e a teoria baseia-se nos conceitos da Análise da Conversação e da Linguística Aplicada, tendo os trabalhos sobre aquisição de segunda língua e/ou língua estrangeira como apoio. As autoras construíram um corpus local oral com um compilado de trechos de entrevistas com um falante nativo e um não nativo da língua inglesa. O corpus é constituído por duas entrevistas com professores de inglês: uma concedida por uma brasileira, e a outra por um inglês que, atualmente, reside no Brasil. A pesquisa tem como objetivo discutir o uso dos marcadores discursivos no texto falado do inglês brasileiro, assinalando suas funções e efeitos de sentido, com o intuito de descrever seu uso. A partir da coleta dos dados, foi feita a descrição dos marcadores discursivos observados, estabelecendo uma relação entre o uso dos marcadores e o processo de aquisição de língua estrangeira, partindo da hipótese de que quanto mais os aprendizes 
utilizarem os marcadores discursivos nas produções em LI, melhor seu desempenho linguístico na língua alvo, já que exercem um papel relevante no estabelecimento de elos coesivos entre as partes do texto, assim como na manutenção e na organização do fluxo conversacional. Os resultados mostraram que tanto o falante nativo da língua inglesa quanto o não nativo criaram estratégias semelhantes no que diz respeito ao planejamento verbal, à organização dos tópicos e à função exercida pelos marcadores discursivos. $\mathrm{O}$ trabalho de Campos e Burgo (2015) não apresenta claramente uma perspectiva ILF em sua construção e a preocupação parece estar mais voltada a uma análise linguística dos marcadores produzidos pelos usuários do que efeitos de interação e comunicação. No entanto, é interessante marcar o resultado da pesquisa que demonstra que os informantes utilizaram estratégias semelhantes para construir suas interações.

Tendo descrito os trabalhos resultantes da nossa pesquisa, é importante ressaltar que, apesar de encontrarmos dez resultados a partir da nossa metodologia, percebemos algumas limitações. Entre elas, por exemplo, está o fato de que temos conhecimento da existência de outros trabalhos com corpus locais e com a perspectiva ILF, tais como o trabalho de Reis e Cruz (2010), que investiga aspectos de pronúncia que impediram a inteligibilidade em interações entre um determinado grupo de falantes utilizando a perspectiva ILF e de LFC. No entanto, em momento algum da pesquisa, esse trabalho apareceu nas buscas realizadas, o que nos leva a supor que isso também pode ter acontecido com outros trabalhos. Outro exemplo é o fato das buscas apresentarem trabalhos que nem sempre tiveram uma perspectiva ILF, embora essa tenha sido uma palavrachave nas buscas. Supomos que pode haver algum tipo de falha nos mecanismos de buscas que pode excluir trabalhos que não incluem o termo "corpus" como palavra-chave no resumo da pesquisa acadêmica ou incluir trabalhos com apenas uma das palavras-chave selecionadas para pesquisa. Isso dificultou muito a 
realização desse mapeamento, pois foram necessários vários recortes até chegarmos a alguns resultados.

Focando na análise dos dez resultados encontrados acima, organizamos uma tabela de acordo com o objetivo da nossa pesquisa, que adota a perspectiva de ILF. Separamos, assim, aqueles trabalhos que adotaram ou não essa perspectiva. Além disso, sendo nossa base os estudos de corpora orais, dividimos também os trabalhos que utilizavam corpora com dados orais; corpora com dados escritos; e aqueles que apresentavam dados orais e escritos.

Tabela 2: Trabalhos com a perspectiva ILF ou não

\begin{tabular}{|l|c|c|}
\hline & PERSPECTIVA ILF & PERSPECTIVA NÃO ILF \\
\hline Corpora orais & OLIVEIRA (2014) & CORSETTI (2015) \\
& & GINEZI (2008) \\
& & CAMPOS E BURGO (2015) \\
\hline Corpora escritos & & TAGNIN (2002) \\
& & WRIGHT (2014) \\
& & COSTES (2014) \\
\hline Corpora orais e escritos & MENONCIN (2013) & SARDINHA (2004) \\
\hline
\end{tabular}

Dos dez resultados, quatro utilizam um corpus local oral, quatro utilizam um corpus local escrito e dois utilizam um corpus local oral e escrito. Dos corpora orais, apenas um se enquadra em um corpus significativo capaz de oferecer dados empíricos para estudiosos de todo país, o Br-ICLE, de Sardinha (2004). No entanto, o principal foco deste trabalho é a catalogação de palavras para o auxílio de aprendizes de inglês, e não o estudo das estratégias de comunicação e a inteligibilidade dos falantes nas interações, o que seria de interesse maior de pesquisadores em ILF. O corpus não apresenta interações completas e apenas demonstra palavras faladas e já catalogadas a partir de ferramentas de busca 
similares ao Wordsmith tools (tais como o concordanciador ${ }^{8}$ ). Com um corpus escrito e palavras faladas catalogadas, é impossível ter acesso à interação mais geral que nasce do contato entre falantes de diferentes LM. Mesmo que algumas palavras sejam retiradas de interações orais, o pesquisador não tem acesso à interação como um todo, o que seria essencial para pesquisas com foco em ILF.

Dentro dessa perspectiva, dos corpora orais, apenas dois adotam a proposta de ILF, o de Oliveira (2014) e o de Menoncin (2013), pois focam na interação multilíngue entre falantes de forma geral, analisando as negociações e acomodações que precisam estabelecer para serem inteligíveis. No entanto, para preencher a lacuna mencionada por Gimenez e Bordini (2014), corpora de cinco ou oito falantes não seriam considerados suficientes para servir de base empírica para os pesquisadores de ILF em grande escala, seja no Brasil ou em outros lugares do mundo. Com o aumento das pesquisas em ILF no Brasil, é muito importante coletarmos material suficiente para embasar nossos estudos com uma perspectiva local. Alguns pontos podem ser destacados para preencher a lacuna existente com os trabalhos baseados em corpus em ILF no Brasil: 1) o Brasil é um país que utiliza o inglês como uma língua estrangeira, e a partir de corpus orais, seria possível motivar estudos com valores bem locais que participam da perspectiva multilíngue da língua inglesa em contexto mais atual; 2) pesquisas baseadas em corpus podem ser a base tanto para trabalhos de cunho linguístico teórico sobre a LI produzida no Brasil quanto de caráter pedagógico, o que tem sido um viés frequente nos estudos em ILF em nosso território.

8 O concordanciador é um programa de computador que constrói concordâncias automaticamente. Na linguística de corpus, os concordanciadores são utilizados para listar as ocorrências de uma determinada palavra ou frase, a qual fica centralizada, com uma quantidade definida de contextos, tanto da esquerda como da direita, fornecendo uma visualização privilegiada do item. De forma geral, muitos concordanciadores, além de produzirem concordâncias, também executam outras funções, como listar a frequência de palavras em um texto ou corpus, extrair palavras-chave, etc. 
Em suma, a partir do nosso mapeamento, percebemos que a lacuna indicada por Gimenez e Bordini (2014) ainda precisa ser preenchida. Uma proposta já em andamento é a criação de um corpus disponibilizado para qualquer tipo de pesquisa em ILF com valores locais de usuários brasileiros. $\mathrm{O}$ projeto BraCE - Brazil Corpus of English ${ }^{9}$ (PORFIRIO, 2017) tem sido desenvolvido desde o início de 2017 e, embora ainda esteja com poucas interações coletadas, já temos alguns resultados disponibilizados para a realização de pesquisas com base em corpus.

\section{CONSIDERAÇÕES FINAIS}

Com a consciência de que acervos como o VOICE (2001) e o ELFA (2004) foram, e ainda são, de extrema importância para a evolução do Inglês como Língua Franca e que as pesquisas em ILF no Brasil estão crescendo cada vez mais, percebemos no mapeamento apresentado aqui que ainda há pouquíssimos trabalhos que consideram a coleta de corpus para a produção de pesquisas em ILF no Brasil. Em nosso estudo, apenas dois trabalhos foram encontrados num período de quase 16 anos, o que demonstra a necessidade de motivarmos pesquisas com essa perspectiva.

Além disso, foi possível observar que não há, no Brasil, nenhuma pesquisa com coleta de corpus em escalas maiores que possa embasar estudos mais locais sobre o inglês produzido em nosso território. Demonstramos aqui que dados empíricos podem, de fato, nos fornecer elementos primordiais para a compreensão das interações em ILF descolando do modelo do falante nativo e procurando construir reflexões a respeito da forma como falantes utilizam seus repertórios multilíngues para comunicar-se de forma efetiva.

9 Disponível em: <www.brace.ufba.br>. 
Destacamos que as pesquisas de cunho pedagógico evidenciadas em mapeamentos anteriores (GIMENEZ; BORDINI, 2014) são de suma importância para motivar discussões a respeito de aspectos importantes para o ensino, tais como a desconstrução do falante nativo, a importância do cunho políticoideológico da língua, a essencialidade da construção de estratégias de comunicação, a compreensão das crenças sobre a língua inglesa na nossa realidade, entre outras. No entanto, apontamos também para o fato de que pesquisas com dados empíricos podem nos fornecer subsídios importantes para discussões tanto linguísticas quanto pedagógicas, sobre os formatos de uso da língua com uma identidade local.

Nesse sentido, a construção de projetos para a criação de corpus/corpora em grande escala que possa servir de auxílio à motivação de pesquisas no Brasil pode ser de grande importância para o crescimento de pesquisas em ILF e fornecer dados empíricos de uma forma mais rápida e mais simplificada para objetivos acadêmicos dos mais diversificados. Esse mapeamento nos demonstrou a importância de seguirmos adiante com o projeto BraCE iniciado em 2017 (PORFIRIO, 2017) com o intuito principal de motivar pesquisas em ILF em território nacional e colocar nosso país em um cenário de contribuição para as reflexões no mundo sobre a perspectiva multilíngue adotada pelos estudos em ILF.

\section{REFERÊNCIAS}

ACE. 2014. The Asian Corpus of English. Director: Andy Kirkpatrick; Researchers: Wang Lixun, John Patkin, Sophiann Subhan. Disponível em: <https://corpus.eduhk.hk/ace/>. Data de acesso: 06 de dezembro de 2017.

ALVES, Anna. Análise das etapas de elaboração de um curso de Inglês com Fins Acadêmicos: fundamentado em corpus. In: I SEMANA DE LÍNGUA ESTRANGEIRA "LINGUAGEM, DIVERSIDADE E REFLEXÃO", 2014, São José do Rio Preto. 
BraCE, 2017. BraCE: Brazil Corpus of English. Projeto de Pesquisa desenvolvido no Instituto de Letras. UFBA. Coordenadora: Lucielen Porfirio. Disponível em: $<$ www.brace.ufba.br>. Data de acesso: 30 de outubro de 2020.

CAMPOS, Michele Ester de Moura Furlan; BURGO, Vanessa Hagemeyer. Marcadores discursivos em entrevistas com falantes nativos e não nativos da língua Inglesa. Guavira Letras, v. 21, p. 80-94, 2015.

COGO, Alessia. ELF and super-diversity: a case study of ELF multilingual practices from a business context. Journal of English as a Lingua Franca 1-2, 2012, p. 287-313.

CORSETTI, Cristiane. Conversational competence in English as a second language: a study of Pragmatic Markers. Rio Grande do Sul: Universidade Católica do Rio Grande do Sul, 2015.

COSTA, Priscilla. Os Phrasal Verbs na produção escrita de aprendizes brasileiros de inglês como segunda língua: uma análise baseasa em corpus. Minas Gerais: UFMG, 2017.

DEWEY, Martin; JENKINS, Jennifer. English as a Lingua Franca in the Global Context: Interconnectedness, Variation and Change. In: SAXENA, Mukul; OMONIYI, Tope. Contending with Globalization in World Englishes. Short Run Press, Great Britain, 2010, p. 90-110.

ELFA 2004. The Corpus of English as a Lingua Franca in Academic Settings. Director: Anna Mauranen. Disponível em: <http://www.helsinki.fi/elfa/elfacorpus $>$. Data de acesso: 05 de junho de 2018.

GINEZI, Luciana. Cafés do Brasil: estudo de variantes em português e inglês na língua falada. 2008. Dissertação (Mestrado em Estudos Linguísticos e Literários em Inglês) Universidade de São Paulo.

GIMENEZ, Telma; BORDINI, Marcella. Estudos sobre Inglês como Língua Franca no Brasil (2005-2012): uma metassíntese qualitativa. Londrina: Signum, 2014. Disponível em: $<$ https://www.researchgate.net/publication/272673817_Estudos_sobre_ingles_como_lin gua_franca_no_Brasil_2005-2012_uma_metassintese_qualitativa $>$. Data de acesso: $30 \mathrm{de}$ outubro de 2020.

GIMENEZ, T.; EL KADRI, M; CALVO, L. C. S.; SIQUEIRA, S.; PORFIRIO, L. Inglês como língua franca: desenvolvimentos recentes. Rev. bras. linguist. apl., Belo Horizonte, v. 15, n. 3, p. 593-619, Sept. 2015. Disponível em: <https://www.scielo.br/pdf/rbla/v15n3/19846398-rbla-15-03-00593>. Data de Acesso: 05 de junho de 2018.

JENKINS, Jennifer. Repositioning English and multilingualism in English as a Lingua Franca. Englishes in Practice 2015; 2(3): 49-85.

JENKINS, Jennifer. The phonology of English as an International Language. Oxford: Oxford University Press, 2001.

MENONCIN, Camila. Competência linguística comunicativa: o inglês como língua franca de funcionários de uma empresa comercial. 2013. Dissertação (Mestrado em Letras Linguagem e Sociedade) - Universidade Estadual do Oeste do Paraná. 
OLIVEIRA, Gabriela. Inglês como Lingua Franca e inteligibilidade de fala: um estudo com usuários brasileiros. 2014. Dissertação (Mestrado em Língua e Cultura) - Universidade Federal da Bahia.

PRODROUMOU, Luke. English as a Lingua Franca: A Corpus-Based Analysis. Continuum, 2008.

REIS, Felipe S.; CRUZ, Neide C. (Un)intelligibility in the context of English as a lingua franca: a study with French and Brazilian speakers. Intercâmbio, v. 22, p. 35-55, 2010.

SARDINHA, Tony Berber. Lingüística de Corpus. São Paulo: Manole, 2004.

SEIDLHOFER, Barbara. Understanding ELF. Oxford: Oxford University Press, 2011.

TAGNIN, Stella; FROMM, Guilherme. CoMAprend - a experiência da construção de um corpus de aprendizes para estudos, 2002.

ViMELF. 2018. Corpus of Video-Mediated English as a Lingua Franca Conversations. Birkenfeld: Trier University of Applied Sciences. Version 1.0. The CASE project. Disponível em: <umwelt-campus.de/case>. Data de acesso: 5 de junho de 2018.

VOICE. 2001. The Vienna-Oxford International Corpus of English (version 2.0 XML). Director: Barbara Seidlhofer; Researchers: Angelika Breiteneder, Theresa Klimpfinger, Stefan Majewski, Ruth Osimk-Teasdale, Marie-LuisePitzl, Michael Radeka. Disponível em: <https://www.univie.ac.at/voice/>. Data de acesso: 05 de junho de 2018.

WRIGHT, Vanessa. Os sintagmas nominais do inglês: um estudo comparativo de corpus entre o uso de determinantes na produção escrita de falantes nativos do inglês e aprendizes brasileiros. 2014. Dissertação (Mestrado em Letras - Linguística) Universidade Federal de Minas Gerais.

Nota do editor:

Artigo submetido para avaliação em: 07 de agosto de 2020.

Aprovado em sistema duplo cego em: 20 de janeiro de 2021. 